\title{
Volumetric changes following ridge preservation or spontaneous healing and early implant placement with simultaneous guided bone regeneration
}

Naenni, Nadja ; Bienz, Stefan P ; Muñoz, Fernando ; Hämmerle, Christoph H F ; Jung, Ronald E ; Thoma, Daniel S

Abstract: AIM To assess volumetric and linear changes following ridge preservation (RP) or spontaneous healing plus early implant placement with or without simultaneous guided bone regeneration (GBR). MATERIALS AND METHODS In eight adult beagle dogs, the mesial roots of the mandibular P3, P4 and M1 were extracted. Sites were randomized to either ridge preservation (RP) or spontaneous healing $(\mathrm{SH})$. Four weeks later dental implants were placed either with (RP2) or without removing non-integrated DBBM (RP1). In RP2 and SH sites, GBR was applied using a demineralized bovine bone mineral and a resorbable membrane. Impressions were taken postextraction (SH)/postridge preservation (RP1; RP2), before and after implant placement and after healing of 4 and 12 weeks. Casts were digitized to allow for superimposition and measurement of contour alterations. RESULTS Median ridge width reduction from postextraction (SH)/postridge preservation (RP1;RP2) to implant placement ranged from $-13.9 \%(\mathrm{SH})$ to $-19.7 \%(\mathrm{RP})(\mathrm{p}>.05)$, whereas from implant placement to sacrifice, it was statistically significantly lower in group RP1 (-5.5\%) compared to group SH $(-23.4 \% ; \mathrm{p}=.0013)$ and group RP2 $(-22.1 \% ; \mathrm{p}=.0026)$. Encompassing the entire study period, median ridge width changes ranged between $-17.8 \%$ $(\mathrm{SH}),-24.8 \%(\mathrm{RP} 2)$ and $-32.5 \%(\mathrm{RP} 1)(\mathrm{p}>.05)$. CONCLUSIONS Irrespective of the treatment modality and the healing period, part of the ridge contour was lost. Early implant placement after ridge preservation without additional GBR resulted in a more stable ridge contour after implant placement compared to controls.

DOI: https://doi.org/10.1111/jcpe. 12860

Posted at the Zurich Open Repository and Archive, University of Zurich

ZORA URL: https://doi.org/10.5167/uzh-150965

Journal Article

Accepted Version

Originally published at:

Naenni, Nadja; Bienz, Stefan P; Muñoz, Fernando; Hämmerle, Christoph H F; Jung, Ronald E; Thoma, Daniel S (2018). Volumetric changes following ridge preservation or spontaneous healing and early implant placement with simultaneous guided bone regeneration. Journal of Clinical Periodontology, 45(4):484-494.

DOI: https://doi.org/10.1111/jcpe. 12860 
Volumetric changes following ridge preservation or spontaneous healing and early implant placement with simultaneous guided bone regeneration

Nadja Naenni ${ }^{1}$, Stefan P. Bienz ${ }^{1}$, Fernando Muñoz ${ }^{2}$, Christoph H.F. Hämmerle ${ }^{1}$, Ronald E. Jung $^{1}$, Daniel S. Thoma ${ }^{1}$

Key words: ridge preservation, volume stability, alveolar ridge augmentation, guided bone regeneration, dental implants $(\mathrm{MeSH})$

Running title: ridge preservation and early implant placement

Number of figures: $x$

Number of tables: $\mathrm{x}$

Address for correspondence: $\quad$ PD Dr. Daniel S. Thoma

Clinic of Fixed and Removable Prosthodontics and Dental Material Science

Center of Dental Medicine, University of Zurich

Plattenstrasse 11

$\mathrm{CH}-8032$ Zurich, Switzerland

Phone: +41446343260

Fax: +41446344305

e-mail: daniel.thoma@zzm.uzh.ch

${ }^{1}$ Clinic of Fixed and Removable Prosthodontics and Dental Material Science, Center of Dental Medicine, University of Zurich, Zurich, Switzerland

${ }^{2}$ Department of Veterinary Clinical Sciences, University of Santiago de Compostela, Lugo, Spain 


\section{Abstract}

Aim: To assess volumetric and linear changes following ridge preservation (RP) or spontaneous healing plus early implant placement with or without simultaneous guided bone regeneration (GBR).

Materials and methods: In eight adult beagle dogs, the mesial roots of the mandibular $\mathrm{P} 3, \mathrm{P} 4$ and $\mathrm{M} 1$ were extracted. Sites were randomized to either ridge preservation (RP) or spontaneous healing $(\mathrm{SH})$. Four weeks later dental implants were placed either with (RP2) or without removing non-integrated DBBM (RP1). In RP2 and SH sites, GBR was applied using a demineralized bovine bone mineral and a resorbable membrane. Impressions were taken post extraction $(\mathrm{SH})$ /post ridge preservation (RP1;RP2), before and after implant placement and after healing of 4 and 12 weeks. Casts were digitized to allow for superimposition and measurement of contour alterations.

Results: Median ridge width reduction from post extraction $(\mathrm{SH}) /$ post ridge preservation $(\mathrm{RP} 1 ; \mathrm{RP} 2)$ to implant placement ranged from $-13.9 \%(\mathrm{SH})$ to $-19.7 \%(\mathrm{RP})(\mathrm{p}>0.05)$, whereas from implant placement to sacrifice it was statistically significantly lower in group RP1(-5.5\%) compared to group $\mathrm{SH}(-23.4 \% ; \mathrm{p}=0.0013)$ and group RP2($22.1 \% ; p=0.0026)$. Encompassing the entire study period, median ridge width changes ranged between $-17.8 \%(\mathrm{SH}),-24.8 \%(\mathrm{RP} 2)$ and $-32.5 \%(\mathrm{RP} 1)(\mathrm{p}>0.05)$.

Conclusions: Irrespective of the treatment modality and the healing period, part of the ridge contour was lost. Early implant placement after ridge preservation without additional GBR resulted in a more stable ridge contour after implant placement compared to controls. 


\section{Clinical Relevance:}

Scientific rationale for the study

Ridge preservation and early implant placement with concomitant GBR is an often performed clinical procedure. Whether bone substitute materials may be left in situ after $\mathrm{RP}$ remained uninvestigated.

\section{Principal findings}

Ridge preservation and subsequent early implant placement without GBR resulted in similar ridge contour changes compared to control groups (spontaneous healing/RP and GBR).

\section{Practical implications}

Implant placement after RP without removing non-integrated DBBM allows avoiding GBR procedures. The results of this study are promising and implicate a less-invasive treatment method. Clinical studies are needed to further support and validate these findings.

\section{Introduction}

Implant placement can take place at different time points following tooth extraction. In order to allow for optimal functional and aesthetic outcomes, all hard and soft tissue alterations need to be considered. Tooth extraction is followed by remodeling processes that lead to a mean resorption of approximately $50 \%$ resulting in a volume loss predominantly at the buccal aspect of the ridge predominantly within the first 3-6 months (Araujo et al., 2005, Schropp et al., 2003, Atwood, 2001). Data from a systematic review report on horizontal changes of $3.79 \mathrm{~mm}( \pm 0.23)$ and vertical reduction of $1.24 \mathrm{~mm}( \pm 0.11)$ at 6 months after tooth extraction (Tan et al., 2012). The resorption of the buccal bone contour can be limited by different approaches employing ridge preservation (Jung et al., 2013, Araujo et al., 2008, Thalmair et al., 2013). These include interventions at the time of tooth extraction aiming to maintain the contour of the 
alveolar bone and thereby facilitating implant placement at a later time point. The placement of a bone substitute material in the extraction socket has been investigated in various pre-clinical and clinical studies (Araujo et al., 2008, Jung et al., 2013, Fickl et al., 2009). These studies demonstrated that ridge preservation techniques failed to completely inhibit the process of remodeling of the socket after tooth extraction, but could promote de novo hard tissue formation and therefore support the maintenance of the ridge profile.

In contrast, spontaneous healing after tooth extraction, followed by implant placement at 6-8 weeks is a frequently performed and well investigated treatment modality (Buser et al., 2011, Sanz et al., 2012). Implant placement at this time-point is often conducted with a simultaneous guided bone regeneration (GBR) procedure and has proven to be successful in terms of implant success (Chen and Buser, 2014, Hammerle et al., 2002). One of the major problems to compare the success of keeping or regenerating soft or hard tissue volume between the two treatment modalities is the fact that, for ridge preservation, the baseline is usually the tissue volume before or after tooth extraction (Schneider et al., 2014, Barone et al., 2016, Zadeh et al., 2016). For studies containing a GBR procedure, baseline is most frequently the ridge width and volume before the intervention (Naenni et al., 2016). Studies which include a GBR procedure and document the volumetric changes from the time-point of tooth extraction are rare (Schneider et al., 2011).

Therefore, the aim of this study was to assess volumetric and linear changes using three treatment modalities: i) ridge preservation (RP) and subsequent early implant placement without guided bone regeneration (GBR); ii) RP and subsequent early implant placement with GBR; iii) spontaneous healing and subsequent early implant placement with simultaneous guided bone regeneration (GBR). 


\section{Material and Methods}

\section{Study Design}

The present study was designed as a randomized controlled experimental study employing 8 adult male beagle dogs (Isoquimen, Barcelona, Spain). The animals had a mean age of 21 months (range 16 to 24 ) and a mean weight of $17,30 \mathrm{~kg}$ (range 15.00 to $20.85 \mathrm{~kg}$ ). The study was performed between July and October 2014 at the animal facility of the Rof Codina Foundation, (Lugo, Spain) according to the guidelines of the Spanish and European regulations about care and use of research animals. Prior to the beginning of the study, the experimental protocol was approved by the local ethical committee (Protocol AELU001/14/INVMED/OUTROS(04)/FMG/04) and was performed according to the ARRIVE guidelines (Kilkenny et al., 2011). The animals were kept in a group kennel, where they had an in- and outdoor area. The dogs had free access to tap water and were fed with granulated dog food that was moistened with water.

\section{Surgical procedures}

All surgical procedures were performed by two surgeons (NN, DT) under general anesthesia and under sterile conditions in an operating room. The dogs were administered medetomine $(0.020 \mathrm{mg} / \mathrm{kg}$ intramuscular, Domtor; Esteve, Barcelona, Spain) and morphine $(0.5 \mathrm{mg} / \mathrm{kg}$ intramuscular, Morfina Braun 2\%, B.Braun Medical, Barcelona, Spain) for premedication on the day of surgery. Subsequently, general anesthesia was induced by an injection of propofol $(3-5 \mathrm{mg} / \mathrm{kg}$ intravenously, Propovet, Abbott Laboratories, Kent, UK) and the dogs were placed on a heating pad for the time of the surgery. Isofluorane (2.5-4\% Isoba-Vet; Schering-Plough, Spain) and O2 (100\%) was used as inhalating anesthetic. Additionally, cefazolin $(20 \mathrm{mg} / \mathrm{kg} / \mathrm{s} . \mathrm{c} . / \mathrm{SID}$, Kurgan; Normon, Spain) and cefovecin ( $8 \mathrm{mg} / \mathrm{kg} / \mathrm{s} . c . / S I D$, Convenia; Zoetis, Spain) was administered for infection prophylaxis. For postoperative pain management morphine $(0.2 \mathrm{mg} / \mathrm{kg} / \mathrm{i} . \mathrm{m} . / \mathrm{SID}$, Metacam; Boehringer Ingelheim, Spain) was given during 5 days. The oral mucosa and the teeth were disinfected three times a week by using gauzes soaked in a $0.12 \%$ chlorhexidine solution (Perio-Aid Tratamiento, Dentaid, Barcelona, 
Spain). Subsequently, a toothbrush and a $0.2 \%$ chlorhexidine gel (Chlorhexidine Bioadhesive Gel, Lacer, Barcelona, Spain) were used for plaque control.

\section{Extractions and ridge preservation procedures}

Local anesthesia (Lidocaine $\mathrm{HCl} 2 \%$ with epinephrine 1:100,000; Henry Schein Inc., Port Washington, NY, USA) was administered by infiltration at the buccal and lingual side of tooth P3, P4 and M1 in one hemi-mandible. The teeth were sectioned in order to prevent them from fracturing and the respective mesial roots were extracted. Root canal treatment and filling with guttapercha and a sealer (AHplus, Dentsply DeTrey, Konstanz, Germany) was performed on the remaining distal roots. The coronal access to the pulp chambers was filled using a temporary filling material (Cavit, 3M ESPE, Neuss, Germany) (Thoma et al., 2010).

In each hemi-mandible three sites (P3, P4, M1) were randomly allocated to three different treatment groups (SH, RP1, RP2). Left and right sides of the mandibles were treated at two different time-points in order to reach a balanced allocation of site and treatment (Fig.1). At surgery I the following interventions were performed:

- RP1; RP2 (two sites)

Ridge preservation with a xenogeneic bone substitute material containing $10 \%$ collagen (DBBM-C; Geistlich Bio-Oss ${ }^{\circledR}$ Collagen, Geistlich Pharma AG, Wolhusen, Switzerland) and a xenogeneic collagen matrix (CMX; Geistlich Mucograft ${ }^{\circ}$ Seal, Geistlich Pharma AG, Wolhusen, Switzerland)

- Spontaneous healing (SH) (one site)

In both RP sites, DBBM-C was placed within the extraction socket up to the level of the bone crest. A collagen matrix (CMX) was placed on top of the bone substitute material and sutured with four single sutures (Dafilon ${ }^{\circledR}$, B.Braun Medical AG, Melsungen, Germany). SH sites were cleaned and rinsed with sterile saline and left for secondary healing. Fig.2 (Thoma et al., 2017) 
The same surgical procedures were repeated on the contralateral side of the mandibles eight weeks later.

\section{Implant placement and GBR procedures}

Four weeks after tooth extraction and ridge preservation/spontaneous healing, all sites were anesthetized using a local anaesthetic (Lidocaine $\mathrm{HCl} 2 \%$ with epinephrine $1: 100,000 ;$ Henry Schein Inc., Port Washington, NY, USA). Surgery II consisted of the following interventions: Following crestal and sulcular incisions around the remaining roots of P3, P4 and M1, a mucoperiosteal flap was raised and a two-piece dental implant (Straumann BoneLevel, 3.3x8mm, Straumann, Basel, Switzerland) placed in each of the three defect sites. All implants were placed flush with the buccal bone plate and slightly lingual to the center of the defect.

At RP1 sites, the implant was placed directly into the socket without removing nonintegrated DBBM-C particles and without any further GBR procedure. At RP2 sites, all non-integrated bone substitute material was removed, the implant placed and GBR performed. At the SH sites, implants were placed with simultaneous GBR (control). For GBR (RP2; control), a bovine bone substitute material (Bio-Oss ${ }^{\circledR}$ Granulat $0.25-1 \mathrm{~mm}$, Geistlich Pharma AG, Wolhusen, Switzerland) was applied filling the infrabony defect without augmenting the buccal contour. The augmented area was covered with a resorbable collagen membrane (Bio-Gide ${ }^{\circledR}$, Geistlich Pharma AG, Wolhusen, Switzerland). The membrane was apically stabilized using two biodegradable pins (Inion GTR $^{\mathrm{TM}}$ Tack, Tampere, Finland). Primary wound closure was obtained applying one horizontal mattress suture and 2-3 single interrupted sutures per site (Gore Tex 5-0 ${ }^{\circledR}$, W.L.Gore \& Associates, Inc, Flagstaff AZ, USA). Fig.3 (Thoma et al., 2017)

\section{Macroscopic evaluation of healing}

At the time of implant surgery (4 weeks after tooth extraction) all sites were visually inspected to classify the healing pattern. Healing was categorized in mature/immature healing for soft tissues and into hard/soft for hard tissue. The soft tissues were inspected 
at the beginning of implant surgery. Hard tissue inspection was performed after flap elevation.

\section{Sacrifice}

Four weeks after the last surgery, all dogs were painlessly sacrificed after sedation with medetomidine $(0.030 \mathrm{mg} / \mathrm{kg} / \mathrm{i} . \mathrm{m}$.$) using an overdose of pentobarbital (60 \mathrm{mg} / \mathrm{kg} / \mathrm{i} . \mathrm{v}$. , Dolethal; Vetoquinol, France). This resulted in endpoints of 4 and 12 weeks post implant placement.

\section{Dental impressions}

Impressions of the mandibles were taken using individualized trays and a polyether impression material (Permadyne, 3M ESPE, Rüschlikon, Schweiz) at the following timepoints: (RP): after extraction and ridge preservation; (SURG): before implant surgery; (IMPL): after implant surgery; (SACR): at the time of sacrifice. Master casts were poured out of dental stone (GC Fujirock type 4®, GC Corp., Tokyo, Japan).

Volumetric and linear analyses to evaluate change of the ridge contour and width The casts were digitized using a 3D scanner (Imetric 3D SA, Courgenay, Switzerland). The obtained surface scans (standard tessellation language, STL) were superimposed using a software (SMOP, Swissmeda AG, Zurich, Switzerland), which allowed for volumetric evaluation (Fig. 4). Super-impositions and all subsequent measurements were performed by one examiner (SB) at the University of Zurich (GLP-like conditions). The ridge width and volumetric differences were assessed for a defined region of interest. Calculations were performed between two different time-points rendering contour alterations for each treatment. This allowed for calculations of each step of treatment as well as for the combined effect of all surgeries. 
Volumetric measurements - buccal

The buccal region of interest (ROI) was selected manually on the baseline surface. The mesio-distal extension accorded to the size of the gap. The bucco-oral dimension was determined as to begin $1 \mathrm{~mm}$ apically from the transition between the buccal and occlusal plane and to extend $4 \mathrm{~mm}$ to the apical (Fig. $4 \mathrm{~b})$. The mean distance ( $\mathrm{mm}$ ) between the surfaces was evaluated for the selected area.

\section{Linear measurements for ridge width changes}

Linear measurements were performed on cross-sections of the obtained and superimposed surface scans. A line was drawn on the top of the crest. One further parallel line was then drawn connecting the buccal with the lingual contour at $2 \mathrm{~mm}$ below the top of the alveolar crest at the time of extraction/ridge preservation (Fig.4d). The ridge width was measured along the line and the changes over time are given as a percentage (\%).

The following calculations for volume alterations and linear changes were performed:

- Effect of ridge preservation: buccal volume alterations as well as ridge width changes between post extraction/ridge preservation and the time of implant placement (RP-SURG)

- Effect of GBR procedure: buccal volume alterations as well as ridge width changes between pre- and post implant placement with simultaneous GBR for the respective group (SURG-IMPL)

- Effect of GBR over time: buccal volume alterations as well as ridge width changes between post-implant placement and sacrifice (IMPL-SACR)

- Effect of all surgeries: buccal volume alterations as well as ridge width changes between the time-point of post ridge preservation and sacrifice (RP-SACR)

\section{Statistical analysis}

Data were recorded in Excel (Microsoft Corporation, Redmond, WA, USA) and statistical analysis was performed with SAS 9.4 (SAS Institute Inc., Cary, NC, USA). Continuous 
parameters were summarized in terms of mean, median, standard deviation and quartiles, subsequently Wilcoxon-Mann-Whitney test as well as parametric mixed models were used for the multifactor investigations. The level of significance was set at $5 \%$ and Bonferroni correction was applied for the multiple group comparisons.

\section{Results}

\section{Macroscopic evaluation of healing}

At the time of implant surgery ( 4 weeks after tooth extraction) all premolar sites had healed uneventfully. Only $75 \%$ of the molar sites, however, showed a mature soft tissue healing. Twenty-five percent of the molar sites displayed a delayed healing pattern without completely matured soft tissue coverage. No difference between SH and RP sites was observed. No exposition of DBBM particles was visible at any of the treated sites. On the level of the bone, $15 \%$ of the premolar sites ( $6 \%$ of the molar sites) were judged as hard and $85 \%$ as soft ( $94 \%$ of the molar sites). All sites considered as "hard" belonged to $\mathrm{SH}$ sites.

\section{Effect of spontaneous healing and ridge preservation (RP-SURG)}

During the healing phase after tooth extraction, the median reduction of the buccal volume amounted to $-1.61 \mathrm{~mm}(\mathrm{Q} 1=-2.06 ; \mathrm{Q} 3=-1.19)$ for ridge preservation $(\mathrm{RP} 1+\mathrm{RP} 2)$ and $-1.42 \mathrm{~mm}(\mathrm{Q} 1=-2.01 ; \mathrm{Q} 3=-0.92)$ for spontaneous healing $(\mathrm{SH})($ Table 1a, Fig. 4a). The corresponding ridge width reduction amounted to $-19.72 \%(\mathrm{Q} 1=-$ 28.23; $\mathrm{Q} 3=-12.52)$ and $-13.97 \%(\mathrm{Q} 1=-19.79 ; \mathrm{Q} 3=-10.60)$. The differences between the groups were statistically not significant $(p>0.05)$.

\section{Effect of implant placement with or without GBR (SURG-IMPL)}

The surgical intervention of implant placement with (RP2 and SH) or without (RP1) GBR lead to a median gain in buccal volume of $0.65 \mathrm{~mm}(\mathrm{Q} 1=0.15 ; \mathrm{Q} 3=1.07)$ for $\mathrm{SH}$ and of $0.31 \mathrm{~mm}(\mathrm{Q} 1=0.23 ; \mathrm{Q} 3=0.92)$ for $\mathrm{RP} 2$, whereas a loss of $-0.28 \mathrm{~mm}(\mathrm{Q} 1=-0.49 ; \mathrm{Q} 3=$ 0.08) was observed for RP1. The corresponding ridge width measurements amounted to 
$30.75 \%(\mathrm{Q} 1=8.96 ; \mathrm{Q} 3=39.28)$ for $\mathrm{SH}, 25.07 \%(\mathrm{Q} 1=10.86 ; \mathrm{Q} 3=35.57)$ for $\mathrm{RP} 2$, and $-2.31 \%(\mathrm{Q} 1=-5.49 ; \mathrm{Q} 3=8.81)$ for RP1 (Table 1b). The values for RP1 were statistically significantly lower in terms of buccal volume $(p=0.0023)$ and ridge width $(p=0.0023)$ compared to SH. Also, the values of RP1 were statistically significantly lower in terms of buccal volume $(p=0.0394)$ and ridge width $(p=0.0384)$ compared to RP2. No interactions were found for site or side. Table $1 b$

\section{Effect of implant placement with or without GBR over time (SURG-SACR)}

During the further healing period post implant placement, the buccal volume generally decreased in all groups over the 6-week healing period as well as over the 14-week healing period (Table 1c, Figure 4b). The median buccal volume decreased statistically significantly to a greater extent for $\mathrm{SH}(-1.55 \mathrm{~mm} ; \mathrm{Q} 1=-1.84 ; \mathrm{Q} 3=-0.72)$ compared to $\mathrm{RP} 1(-0.05 \mathrm{~mm} ; \mathrm{Q} 1=-0.43 ; \mathrm{Q} 3=-0.01 ; \mathrm{p}=0.0004)$ and RP2 $(-0.85 \mathrm{~mm} ; \mathrm{Q} 1=-0.96$; $\mathrm{Q} 3=-0.60 ; \mathrm{p}=0.0207$ ) for the 6-week healing period; however, the corresponding ridge width measurements did not show any statistically significant differences. For the 14week healing period, the median reduction of the ridge width of RP1 $(-5.45 \%$; $1=-$ 15.99; Q3=1.26) was statistically significantly lower compared to SH $(-23.36 \%$; $1=-$ 42.50; $\mathrm{Q} 3=-14.79 ; \mathrm{p}=0.0013)$, and also compared to RP2 $(-22.10 \% ; \mathrm{Q} 1=-29.63 ; \mathrm{Q} 3=$ $-17.87 ; p=0.0026)$. No further differences were found, however, the site had an influence on the 14-week ridge width comparison. While the reduction was consistently low in RP1, the reduction was higher for molar sites compared to premolar sites in group $\mathrm{SH}$.

\section{Effect of all surgeries (RP-SACR)}

Over the entire study period, the median loss of buccal volume accounted for $-1.53 \mathrm{~mm}$ $(\mathrm{Q} 1=-2.37 ; \mathrm{Q} 3=-0.88)$ in group $\mathrm{SH} ;-1.64 \mathrm{~mm}(\mathrm{Q} 1=-1.77 ; \mathrm{Q} 3=-1.17)$ in group $\mathrm{RP2}$ and $-1.90 \mathrm{~mm}(\mathrm{Q} 1=-3.29 ; \mathrm{Q} 3=-1.69)$ in group $\mathrm{RP} 1$, all at 14 weeks. The median reduction of the ridge width ranged from $-17.88 \%(\mathrm{SH}$ at 14 weeks; $\mathrm{Q} 1=-43.39 ; \mathrm{Q} 3=-$ 9.92), $-24.83 \%(\mathrm{RP} 2$ at 14 weeks; $\mathrm{Q} 1=-28.61 ; \mathrm{Q} 3=-12.45)$ and $-32.55 \%(\mathrm{RP} 1$ at 14 weeks; $\mathrm{Q} 1=-52.22 ; \mathrm{Q} 3=-18.82)($ Table 1c, Figure 4c). Although RP1 sites did loose a considerable higher amount regarding ridge width and buccal volume, no statistically 
significant effects were observed for all measurements for both healing periods. Thus, the results reveal similar outcomes for RP1-sites where DBBM was not removed at implant placement compared to groups RP2 and SH. However, the site had an influence on the buccal volume measurements for the 6-week healing period, tending to a higher loss of volume in the molar region.

\section{Discussion}

The present study revealed that: i) all three treatment modalities resulted in similar buccal volume and ridge width changes between post extraction (SH)/post ridge preservation (RP1;RP2) and implant placement; ii) implant placement in conjunction with GBR (SH, RP2) increased the buccal volume and ridge width compared to sites without GBR (RP1); iii) during the healing following implant placement, more ridge width was lost in sites with GBR (SH, RP2) compared to sites without GBR (RP1); iv) encompassing the entire study period, none of the treatment modalities was significantly different from the other.

Various clinical concepts exist in order to limit bone remodeling processes after tooth extraction and to regenerate missing volume. This includes e.g. spontaneous healing, subsequent implant placement with concomitant guided bone regeneration (GBR) or ridge preservation procedures and subsequent implant placement with or without simultaneous GBR. From a clinical point of view, treatment strategies should aim at optimizing the ridge width and volume, minimizing the number and invasiveness of surgical interventions, reducing costs and patient morbidity. In the present study, three concepts were compared in terms of ridge width and buccal volume changes between tooth extraction, implant placement and a subsequent healing period of up to 12 weeks. The three therapeutic treatment modalities rendered changes in ridge width/buccal volume of $31.20 \% /-1.9 \mathrm{~mm}$ (ridge preservation and subsequent implant placement), $22.23 \% /-1.6 \mathrm{~mm}$ (ridge preservation and subsequent implant placement with GBR), $24.65 \%$ / $-1.5 \mathrm{~mm}$ (spontaneous healing and subsequent implant placement with GBR). This demonstrated that regarding buccal volume change, no benefit of performing an additional GBR procedure at implant placement (RP2 vs. RP1) could be 
observed. Surprisingly, even the sites in group RP2 and SH resulted in very similar volume change. In group SH no ridge preservation procedure was performed and thus, more volume was lost during the healing phase before implant placement. This loss however, was compensated with the simultaneous GBR procedure performed at implant placement. According to the above-mentioned results and compared to spontaneous healing, ridge preservation performed at the time of extraction seems not to lead to better volume preservation compared to early implant placement with simultaneous GBR. Nevertheless, a slightly higher amount of volume change was achieved in group RP1. Considering costs, spontaneous healing followed by implant placement and GBR compared to ridge preservation without further GBR at implant placement might be similar. Additionally, considering clinical feasibility, ease of treatment, invasiveness and morbidity, performing a flapless RP procedure and subsequent implant placement without GBR might be beneficial compared to spontaneous healing and the need to raise a full flap to perform an additional buccal GBR procedure. In contrast, performing an RP and an additional GBR procedure (RP2) at the time of implant placement seems to be not only in terms of cost, but also in terms of invasiveness, a questionable therapeutical option considering the outcomes of the present study.

Ridge preservation is a widely accepted procedure applied to minimize volume loss following tooth extraction (Thoma et al., 2017). Although ridge preservation procedures cannot prevent from distinct bone remodeling processes, they limit a ridge collapse and might therefore facilitate subsequent implant placement (Avila-Ortiz et al., 2014). Based on preclinical and clinical studies, a complete prevention of volume loss can not be achieved by applying ridge preservation procedures (Araujo and Lindhe, 2009, Thalmair et al., 2013). In the present study, during the 4-week healing period following tooth extraction and spontaneous healing (SH) or ridge preservation (RP), the buccal tissue volume could not be fully maintained in neither one of the two groups, although all sites presented with intact bone walls. Both groups lost buccal volume during the healing phase ranging between 1.4 and $1.6 \mathrm{~mm}$, which corresponded to a loss of $14-20 \%$ of the ridge width. The volume loss observed in the present study is in line with previously 
published data (Jung et al., 2013). The effect of buccal volume change was not statistically significant between the two groups, but slightly in favor of spontaneous healing. Hence, an immediate ridge preservation did not yield beneficial osseous volume contribution before implant placement. This would - focusing on buccal volume changes clinically indicate no further benefit of performing a ridge preservation procedure at intact extraction sockets if early implant placement is considered. One might speculate, however, that further changes of the ridge contour have to be expected, since available data from clinical studies demonstrated more efficient ridge maintenance when using RP compared to spontaneous healing up to 6 months (Araujo et al., 2008, Fickl et al., 2009). Four weeks of healing corresponds to early implant placement in the clinic. The intention when placing implants at this early stage after tooth extraction is not to obtain bone healing, but a healed (e.g. closed) soft tissue situation. This simplifies primary wound closure at the time of (early) implant placement. Histologically, in order to obtain bone healing, 4-6 months are needed following ridge preservation. From a clinical point of view, this increases the treatment time. The research question therefore was, whether or not implants can be placed early and will still obtain osseointegration. Moreover, to analyse volume and linear changes based on the two treatment concepts: early placement plus additional GBR (traditional approach), early placement without further GBR (newer approach reducing costs (no further GBR, and reducing time (shortened treatment time).

The surgical intervention of implant placement and concomitant GBR (RP2 and SH), demonstrated a slight increase in buccal volume. In contrast, RP1 sites (no GBR), even demonstrated a loss in buccal volume and ridge width. These outcomes might be explained by the fact that in order to perform a GBR procedure (without overcontouring the ridge) a more extensive flap had to be raised and periosteal releasing incisions were made in these regions to allow for a tension-free wound closure. Such an intervention might, on the contrary, have caused a more pronounced swelling in GBR sites (RP2 and $\mathrm{SH})$. As opposed to the measured volume gain at the time of the second surgery (implant placement), a later loss in volume might be expected due to healing of the site. 
As a consequence of flap elevation bone is exposed and the following re-establishment of the periosteum will have an influence on the healing as well as on further volume change.

During the further healing period of up to 14 weeks following implant placement, the buccal ridge contour decreased in all groups. Interestingly, RP1 sites demonstrated significantly less buccal volume loss compared to GBR-treated sites ( $\mathrm{SH}, \mathrm{RP2}$ ). This loss of the buccal contour could at least in part be explained by the volume gain at implant surgery in GBR groups that was probably caused by the swelling. In addition, one might speculate on the limited volume stability of the GBR sites over time as the reason why RP1 resulted in an overall more stable ridge contour between implant placement and 14 weeks. Based on in vitro data analyzing the effect of wound closure on changes of the ridge contour, GBR at implant sites results in a loss of ridge contour immediately post surgery (Jung et al., 2013, Jung, 2017, Mardas et al., 2011), as well as over time in a clinical setting (Mir-Mari et al., 2016). In contrast, RP1 sites demonstrated a better stability of the ridge contour. In these sites, the extraction socket was debrided at one single time-point only (at the day of tooth extraction). At implant placement, the buccal aspect of the former extraction socket including the bone substitute remained untouched. This could explain to some extent these more favorable outcomes between implant placement and subsequent 14-week healing period compared to sites that were being debrided twice (SH, RP2), both at the time of extraction and at implant surgery, followed by re-augmentation using a GBR technique.

The bone substitute material placed into the extraction sockets remains loosely integrated in case of early implant placement, and so far, is often removed at the time of implant placement. Whether this procedure is indicated, remains questionable according to the results of the present study. It seems though, that if removed, an additional regenerative procedure (e.g. GBR) is needed to achieve the desired volume. Results from a recently published systematic review seem to support this. Less additional GBR was needed in case of implant placement after RP procedures in mostly intact extraction sockets (Mardas et al., 2015). 
The outcomes of the present study are to some extent limited by the inclusion of molar and premolar sites and the lack of a further control group (no GBR at implant placement in $\mathrm{SH}$ sites). Some of these limitations were overcome by applying statistical analyses of confounding factors. Due to the lack of more sites available, no further control group could be added. In general, the results from this study should be looked at bearing in mind that the sample size was limited in order to keep the number of animals low. Furthermore, the observed results will have to be confirmed in a clinical setting. Still, this study widens the knowledge on volumetric changes including all steps during the entire clinical procedure without isolating the phase before implant placement until follow up. Thus, it might help to establish new therapeutic concepts. The effect of the different treatments regarding histomorphometric outcomes have been published in a previous paper (Thoma et al., 2017) and support the volumetric and linear results obtained and also showed no significant differences between the three treatment groups. Whether a future procedure could consist of leaving non-integrated DBBM after ridge preservation at the time of implant placement has to be investigated separately in a clinical setting. This approach seems to be promising considering invasiveness, patient morbidity and costs.

\section{Conclusion}

Irrespective of the treatment modality, part of the ridge contour is lost. Early implant placement after ridge preservation without additional GBR resulted in a more stable ridge contour from the time of implant placement until sacrifice compared to controls. These findings do not exclude a probable necessity of additional soft tissue augmentation procedure in high aesthetic regions. Furthermore, the obtained results will have to be validated for clinical applicability. 


\section{Acknowledgements and Conflict of Interest}

The authors would like to acknowledge Prof. Dr. Jürg Hüsler (for his support in the statistical analysis of the data) and Dr. Francine Brandenberg for performing part of the surgeries, both Clinic of Fixed and Removable Prosthodontics and Dental Material Science, Center of Dental Medicine, University of Zurich, Zurich, Switzerland. The support and help of the animal care team at the Facultad de Veterinaria, Campus Universitario $\mathrm{s} / \mathrm{n}$, Lugo, Spain is greatly appreciated. This study was funded by the Clinic of Fixed and Removable Prosthodontics and Dental Material Science, Center of Dental Medicine, University of Zurich, Zurich, Switzerland and by a research grant of Geistlich Pharma AG, Wolhusen, Switzerland. The authors report no conflict of interest for this study. 


\section{Figure Legends}

Fig. 1

Timeline showing the groups, sides and the respective surgical procedures as well as the healing phases.

Fig. 2

Clinical pictures representing the surgical procedures (extraction, root canal treatment, ridge preservation). a. preoperative view. b. Mesial roots of P3, P4 and M1 extracted and root canal treatments performed in distal roots of P3, P4 and M1. c. control x-ray after extraction and root canal treatment. d. Deproteinized bovine bone material with $10 \%$ collagen (DBBM-C) has been placed in sites P4 and M1 (RP), coagulum in site P3. e. A collagen matrix has been sutured in RP sites (P3, M1).

\section{Fig. 3}

Clinical pictures representing implant placement and guided bone regeneration (GBR). a. preoperative view. b. reflected full-thickness flaps. c. all granulation tissue has been removed in sites P3 (SH) and M1 (RP2). No removal of deproteinized bovine bone material with $10 \%$ collagen (DBBM-C) in site P4 (RP1). d. implants were placed flush with the buccal bone crest. e. control x-ray after implant placement. f. Deproteinized bovine bone material granules (DBBM) are placed around the infrabony defects in groups SH (P3) and RP2 (M1). The buccal contour is not augmented. No GBR is applied in group RP1 (P4). g. the collagen membranes are immobilized in the apical region using resorbable pins and placed over the sites P3 (SH) and M1 (RP2). h. tension-free wound closure.

Fig.4

a_Occlusal view of the superimposed scans of digitized casts at the different time-points. Yellow (RP): Post extraction (SH) / post ridge preservation (RP1;RP2); Green (SURG): before implant surgery; Grey (IMPL): after implant surgery; Orange (SACR): at the time of sacrifice 
b_Buccal view of the region of interest (ROI) on the baseline surface.

Yellow (RP): Post extraction sham site; Green (SACR) sham site at sacrifice

c_Buccal view of the change in ROI over the entire study period from Yellow (RP) to Green (SACR).

c_Cross-sectional view of the measurements for the ridge width (changes).

Blue line level with the occlusal surface and blue vector at $2 \mathrm{~mm}$ below the ridge crest indicate the levels, where the measurements were performed.

\section{Fig. 5}

a_Boxplots representing the distribution of changes in buccal volume and ridge width for both groups ( $\mathrm{SH} ; \mathrm{RP})$ for the time between post extraction / post ridge preservation and implant placement.

b_Effect of implant placement with / without additional GBR. Values for both healing periods and the time between implant placement and sacrifice are depicted.

C_Effect of all surgeries from post extraction / post ridge preservation until sacrifice. Treatment $=$ Groups $\mathrm{RP} 2, \mathrm{RP} 1, \mathrm{SH} ; \mathrm{RP}=$ ridge preservation; $\mathrm{SH}=$ sham site, spontaneous healing; RP2 = ridge preservation and implant placement after removal of DBBM-C and additional GBR; RP1= ridge preservation without removing DBBM-C and implant placement without $\mathrm{GBR} ; \mathrm{SH}=$ spontaneous healing and implant placement with $\mathrm{GBR}$; T_Sacr $=6$ weeks and 14 weeks of healing after implant placement and GBR.

Table 1

a_Effect of Ridge preservation and spontaneous healing. Calculations for buccal volume and ridge width.

b_Effect of implant surgery without (RP1) and with (RP2; SH) concomitant GBR procedure.

C_ Effect over time from Implant placement until sacrifice (IMPL-SACR) and for all surgeries (RP-SACR) for all 3 groups und 2 time points 
Group ( $\mathrm{RP}=$ ridge preservation; $\mathrm{SH}=$ spontaneous healing); Variable=buccal volume, ridge width; Mean; Std = standard deviation; Min= minimun; Q1= 1st quartile; Median; Q3= 3rd quartile, Max= maximum. 


\section{References}

Araujo, M., Linder, E., Wennstrom, J. \& Lindhe, J. (2008) The influence of Bio-Oss Collagen on healing of an extraction socket: an experimental study in the dog. International Journal of Periodontics and Restorative Dentistry 28, 123-135.

Araujo, M. G. \& Lindhe, J. (2009) Ridge preservation with the use of Bio-Oss collagen: A 6-month study in the dog. Clinical Oral Implants Research 20, 433-440. doi:10.1111/j.1600-0501.2009.01705.x.

Araujo, M. G., Sukekava, F., Wennstrom, J. L. \& Lindhe, J. (2005) Ridge alterations following implant placement in fresh extraction sockets: an experimental study in the dog. Journal of Clinical Periodontology 32, 645-652. doi:10.1111/j.1600051X.2005.00726.x.

Atwood, D. A. (2001) Some clinical factors related to rate of resorption of residual ridges. 1962. Journal of Prosthetic Dentistry 86, 119-125.

Avila-Ortiz, G., Elangovan, S., Kramer, K. W., Blanchette, D. \& Dawson, D. V. (2014) Effect of alveolar ridge preservation after tooth extraction: a systematic review and meta-analysis. Journal of Dental Research 93, 950-958. doi: $10.1177 / 0022034514541127$.

Barone, A., Toti, P., Quaranta, A., Alfonsi, F., Cucchi, A., Calvo-Guirado, J. L., Negri, B., Di Felice, R. \& Covani, U. (2016) Volumetric analysis of remodelling pattern after ridge preservation comparing use of two types of xenografts. A multicentre randomized clinical trial. Clinical Oral Implants Research 27, e105-e115. doi: $10.1111 / \mathrm{clr} .12572$.

Buser, D., Wittneben, J., Bornstein, M. M., Grutter, L., Chappuis, V. \& Belser, U. C. (2011) Stability of contour augmentation and esthetic outcomes of implantsupported single crowns in the esthetic zone: 3-year results of a prospective study with early implant placement postextraction. Journal of Periodontology 82, 342-349. doi:10.1902/jop.2010.100408.

Chen, S. T. \& Buser, D. (2014) Esthetic outcomes following immediate and early implant placement in the anterior maxilla--a systematic review. International Journal of Oral and Maxillofacial Implants 29 Suppl, 186-215. doi:10.11607/jomi.2014suppl.g3.3.

Fickl, S., Schneider, D., Zuhr, O., Hinze, M., Ender, A., Jung, R. E. \& Hurzeler, M. B. (2009) Dimensional changes of the ridge contour after socket preservation and buccal overbuilding: an animal study. Journal of Clinical Periodontology 36, $442-$ 448. doi:10.1111/j.1600-051X.2009.01381.x.

Hammerle, C. H., Jung, R. E. \& Feloutzis, A. (2002) A systematic review of the survival of implants in bone sites augmented with barrier membranes (guided bone 
regeneration) in partially edentulous patients. Journal of Clinical Periodontology 29 Suppl 3, 226-231; discussion 232-223.

Jung, R. (2017) Combined use of xenogenic bone substitute material covered with a native bilayer collagen membrane for alveolar ridge preservation: A randomized controlle clinical trial. Clinical Oral Implants Research.

Jung, R. E., Philipp, A., Annen, B. M., Signorelli, L., Thoma, D. S., Hammerle, C. H., Attin, T. \& Schmidlin, P. (2013) Radiographic evaluation of different techniques for ridge preservation after tooth extraction: a randomized controlled clinical trial. Journal of Clinical Periodontology 40, 90-98. doi:10.1111/jcpe.12027.

Kilkenny, C., Browne, W., Cuthill, I. C., Emerson, M. \& Altman, D. G. (2011) Animal research: reporting in vivo experiments--the ARRIVE guidelines. Journal of Cerebral Blood Flow and Metabolism 31, 991-993. doi:10.1038/jcbfm.2010.220.

Mardas, N., D'Aiuto, F., Mezzomo, L., Arzoumanidi, M. \& Donos, N. (2011) Radiographic alveolar bone changes following ridge preservation with two different biomaterials. Clinical Oral Implants Research 22, 416-423. doi:10.1111/j.16000501.2010.02154.x.

Mardas, N., Trullenque-Eriksson, A., MacBeth, N., Petrie, A. \& Donos, N. (2015) Does ridge preservation following tooth extraction improve implant treatment outcomes: a systematic review: Group 4: Therapeutic concepts \& methods. Clinical Oral Implants Research 26 Suppl 11, 180-201. doi:10.1111/clr.12639.

Mir-Mari, J., Wui, H., Jung, R. E., Hammerle, C. H. \& Benic, G. I. (2016) Influence of blinded wound closure on the volume stability of different GBR materials: an in vitro cone-beam computed tomographic examination. Clinical Oral Implants Research 27, 258-265. doi:10.1111/clr.12590.

Naenni, N., Schneider, D., Jung, R. E., Husler, J., Hammerle, C. H. \& Thoma, D. S. (2016) Randomized clinical study assessing two membranes for guided bone regeneration of peri-implant bone defects: clinical and histological outcomes at 6 months. Clinical Oral Implants Research. doi:10.1111/clr.12977.

Sanz, I., Garcia-Gargallo, M., Herrera, D., Martin, C., Figuero, E. \& Sanz, M. (2012) Surgical protocols for early implant placement in post-extraction sockets: a systematic review. Clinical Oral Implants Research 23 Suppl 5, 67-79. doi:10.1111/j.1600-0501.2011.02339.x.

Schneider, D., Grunder, U., Ender, A., Hammerle, C. H. \& Jung, R. E. (2011) Volume gain and stability of peri-implant tissue following bone and soft tissue augmentation: 1-year results from a prospective cohort study. Clinical Oral Implants Research 22, 28-37. doi:10.1111/j.1600-0501.2010.01987.x.

Schneider, D., Schmidlin, P. R., Philipp, A., Annen, B. M., Ronay, V., Hammerle, C. H., Attin, T. \& Jung, R. E. (2014) Labial soft tissue volume evaluation of different techniques for ridge preservation after tooth extraction: a randomized controlled 
clinical trial. Journal of Clinical Periodontology 41, 612-617.

doi:10.1111/jcpe.12246.

Schropp, L., Wenzel, A., Kostopoulos, L. \& Karring, T. (2003) Bone healing and soft tissue contour changes following single-tooth extraction: a clinical and radiographic 12-month prospective study. International Journal of Periodontics and Restorative Dentistry 23, 313-323.

Tan, W. L., Wong, T. L., Wong, M. C. \& Lang, N. P. (2012) A systematic review of postextractional alveolar hard and soft tissue dimensional changes in humans. Clinical Oral Implants Research 23 Suppl 5, 1-21. doi:10.1111/j.16000501.2011.02375.x.

Thalmair, T., Fickl, S., Schneider, D., Hinze, M. \& Wachtel, H. (2013) Dimensional alterations of extraction sites after different alveolar ridge preservation techniques - a volumetric study. Journal of Clinical Periodontology 40, 721-727. doi:10.1111/jcpe.12111.

Thoma, D. S., Jung, R. E., Schneider, D., Cochran, D. L., Ender, A., Jones, A. A., Gorlach, C., Uebersax, L., Graf-Hausner, U. \& Hammerle, C. H. (2010) Soft tissue volume augmentation by the use of collagen-based matrices: a volumetric analysis. Journal of Clinical Periodontology 37, 659-666. doi:10.1111/j.1600051X.2010.01581.x.

Thoma, D. S., Naenni, N., Benic, G. I., Munoz, F., Hammerle, C. H. F. \& Jung, R. E. (2017) Effect of ridge preservation for early implant placement - is there a need to remove the biomaterial? Journal of Clinical Periodontology 44, 556-565. doi:10.1111/jcpe.12709.

Zadeh, H. H., Abdelhamid, A., Omran, M., Bakhshalian, N. \& Tarnow, D. (2016) An open randomized controlled clinical trial to evaluate ridge preservation and repair using SocketKAP() and SocketKAGE() : part 1-three-dimensional volumetric soft tissue analysis of study casts. Clinical Oral Implants Research 27, 640-649. doi: $10.1111 / \mathrm{clr} .12714$. 


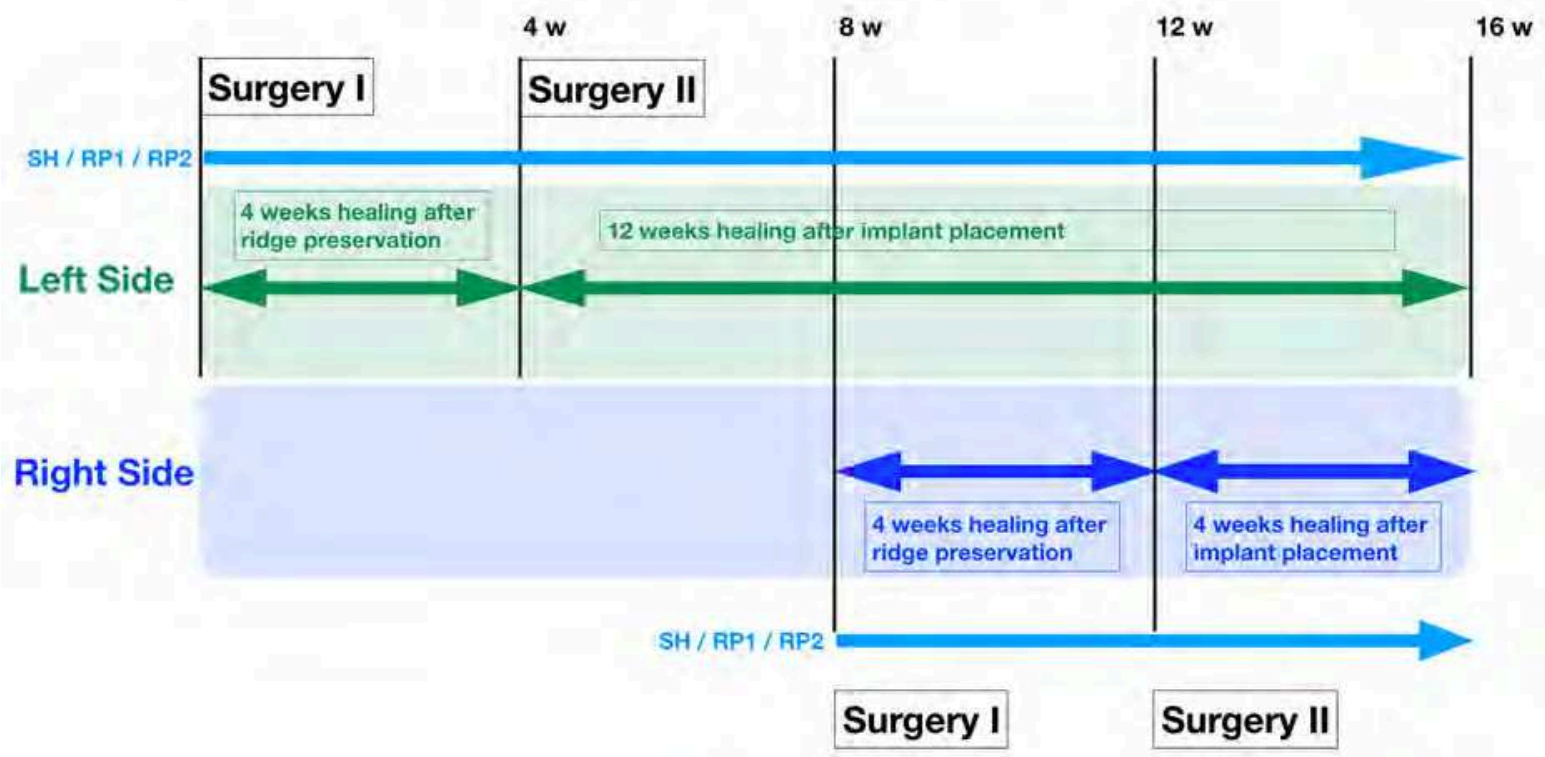

Surgery I: Extraction and

Ridge preservation (RP)

OR spontaneous healing (SH)

Surgery II: Implant placement

without removal of DBBM and without guided bone regeneration (GBR) (RP1)

with removal of DBBM, but with GBR (RP2)

with simultaneous GBR (SH)

Figure 1

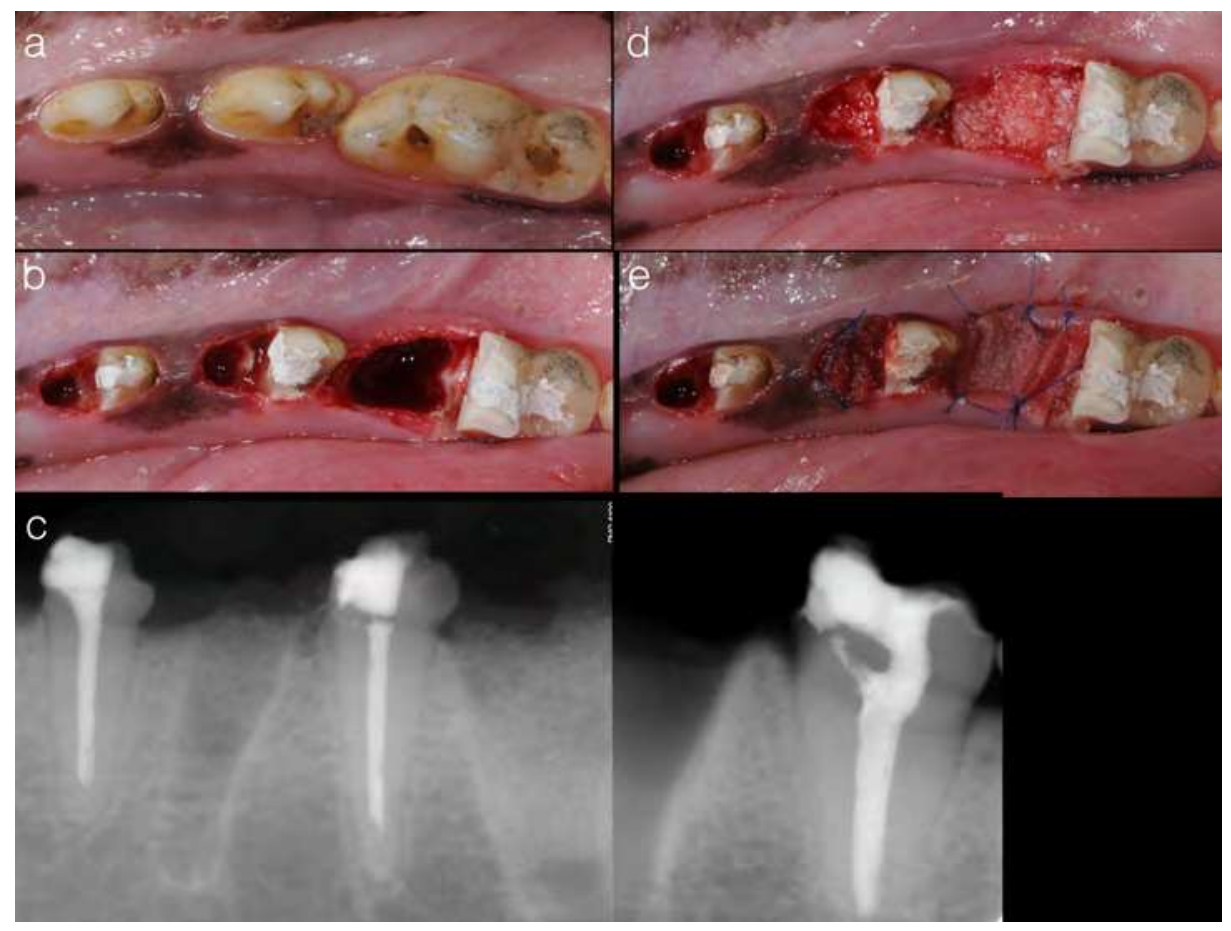

Figure 2 


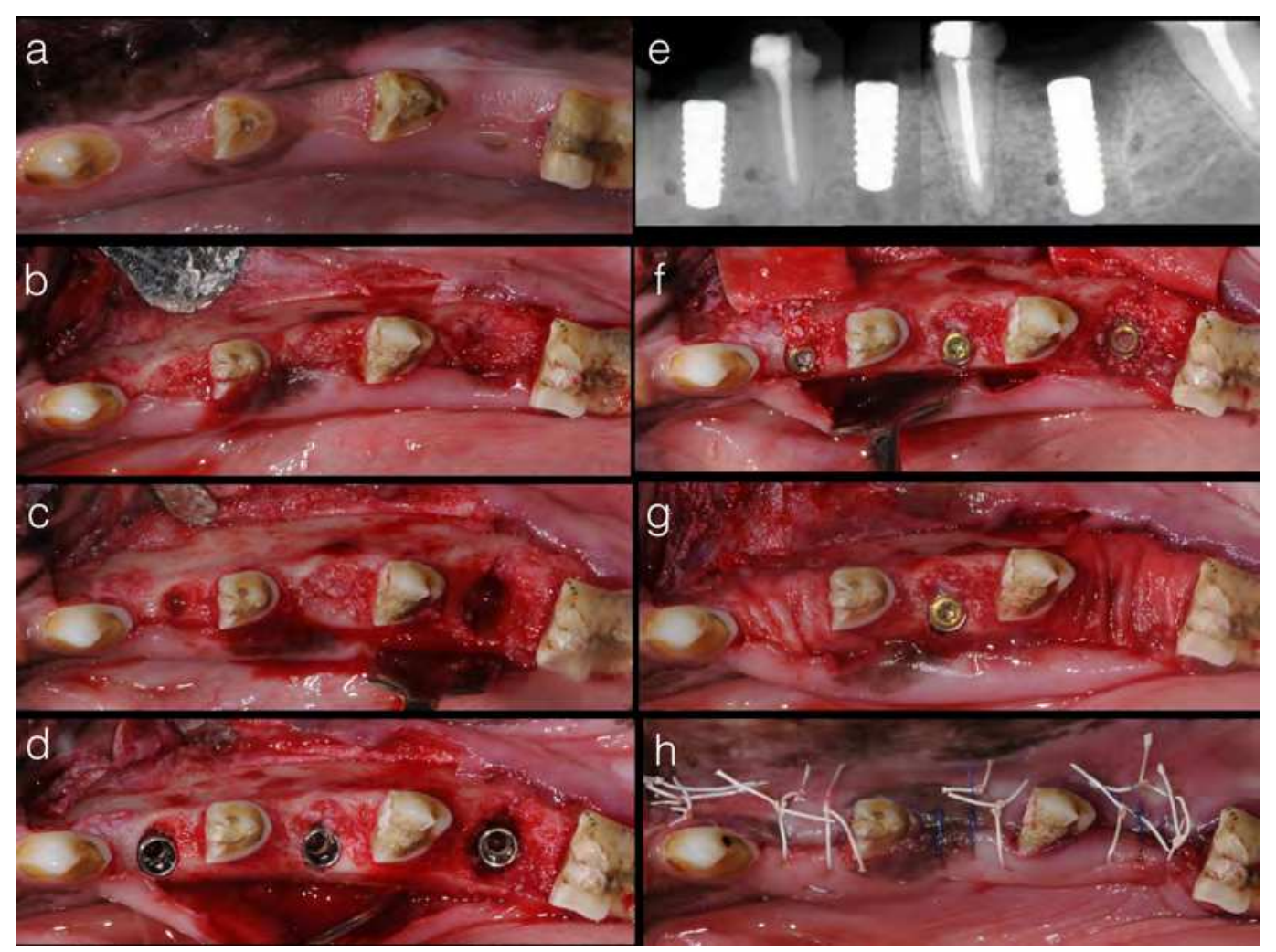

Figure 3
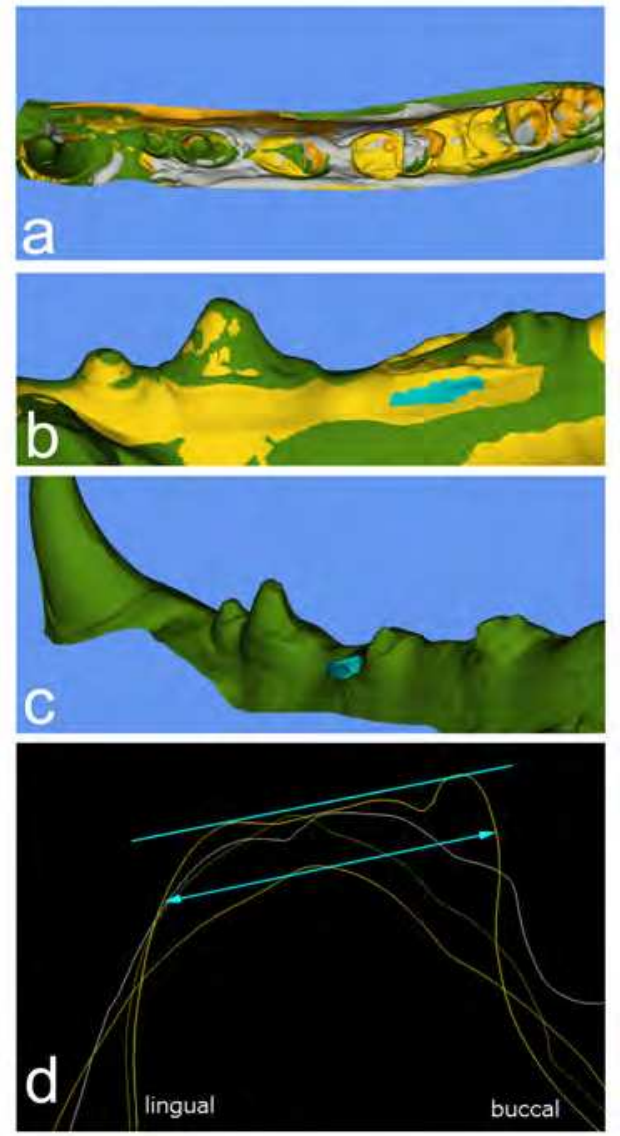

Figure 4 

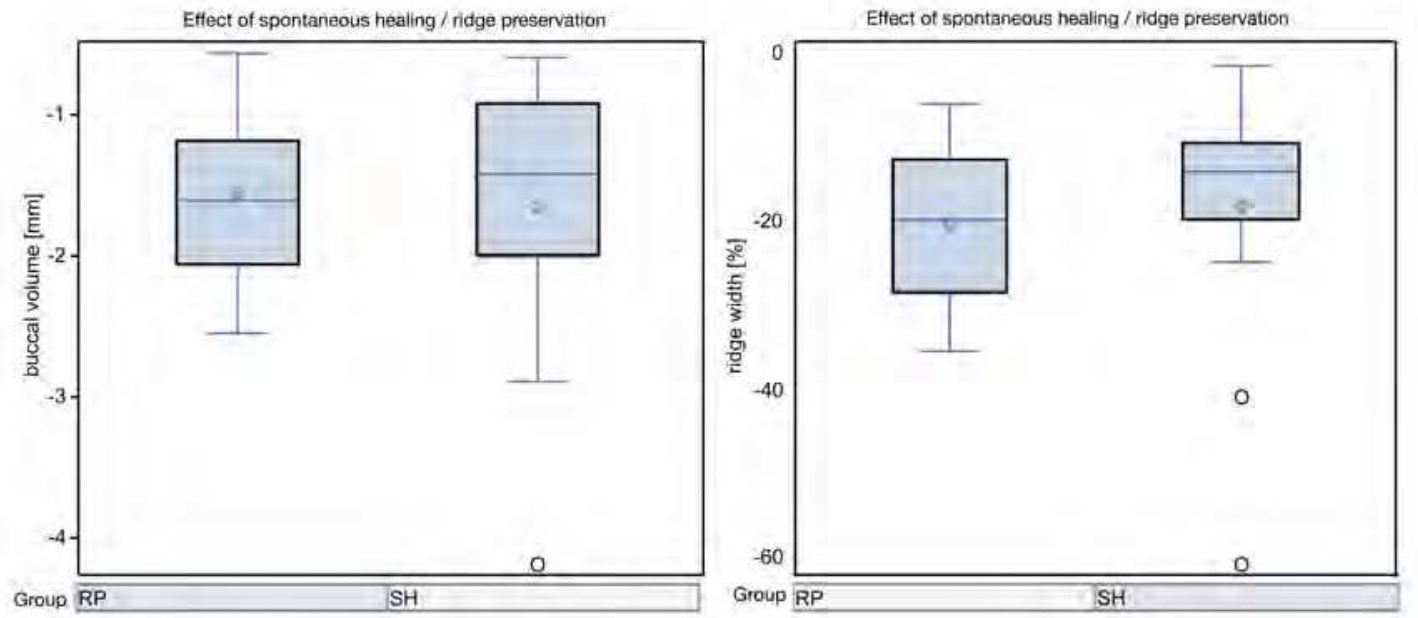

Figure 5a
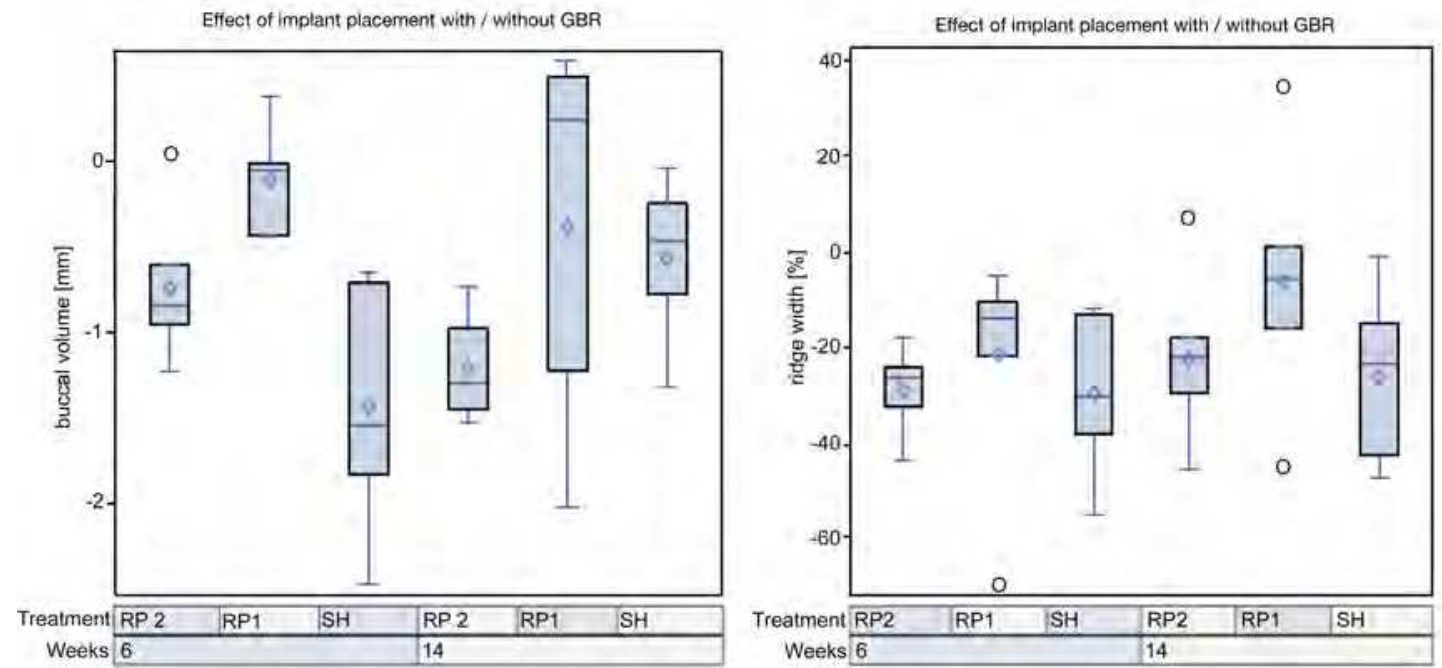

Figure $5 b$
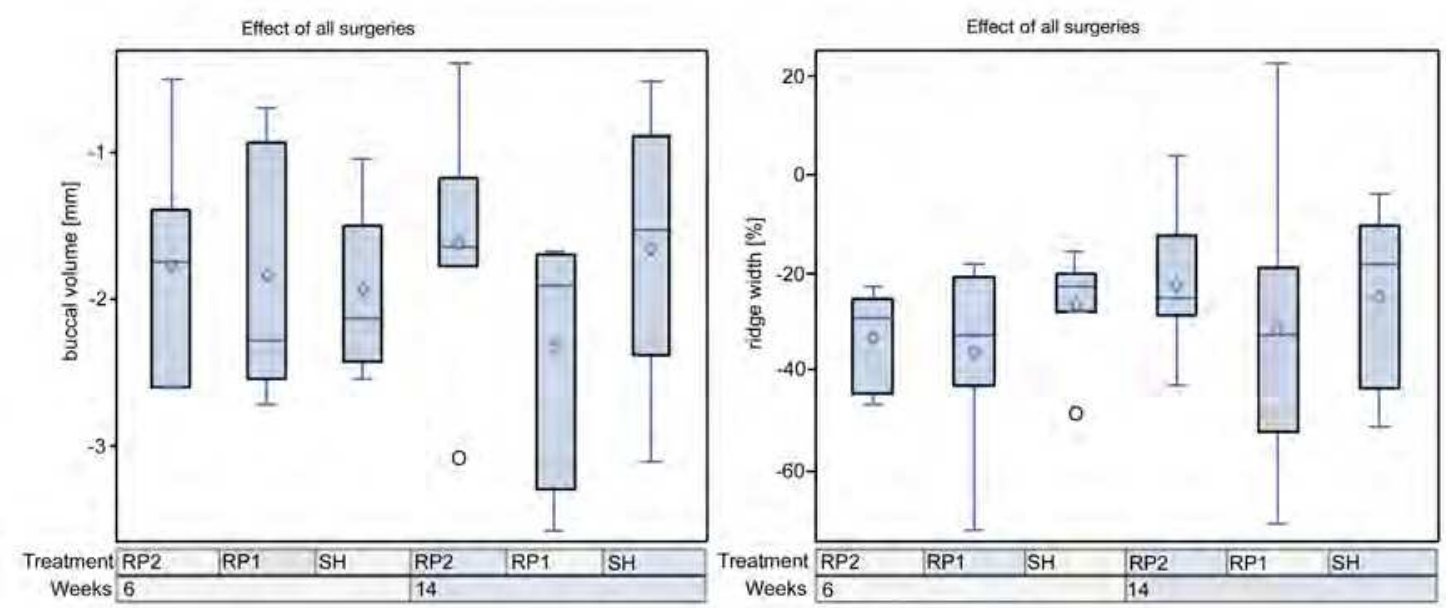

Figure 5c 
Table 1

$1 a$

$\begin{array}{ll}\text { Group } & \text { Variable } \\ \text { RP } & \text { buccal volume } \\ \text { SH } & \text { buccal volume } \\ \text { RP } & \text { ridge width } \\ \text { SH } & \text { ridge width }\end{array}$

\begin{tabular}{lllllll} 
Mean & Std & Min & \multicolumn{1}{l}{ Q1 } & Median & Q3 & Max \\
-1.555 & 0.585 & -2.550 & -2.060 & -1.610 & -1.190 & -0.570 \\
-1.650 & 0.950 & -4.190 & -2.010 & -1.415 & -0.915 & -0.600 \\
-20.271 & 8.420 & -35.404 & -28.227 & -19.720 & -12.516 & -5.964 \\
-18.238 & 14.338 & -60.817 & -19.790 & -13.969 & -10.601 & -1.471
\end{tabular}

$1 b$

$\begin{array}{ll}\text { Group } & \text { Variable } \\ \text { RP1 } & \text { buccal volume } \\ \text { RP2 } & \text { buccal volume } \\ \text { SH } & \text { buccal volume } \\ \text { RP1 } & \text { ridge width } \\ \text { RP2 } & \text { ridge width } \\ \text { SH } & \text { ridge width }\end{array}$

\begin{tabular}{|c|c|c|c|c|c|c|}
\hline Mean & Std & Min & Q1 & Media & Q3 & Max \\
\hline-0.127 & 0.505 & -0.700 & -0.490 & -0.280 & 0.080 & 1.020 \\
\hline 0.477 & 0.523 & -0.570 & 0.230 & 0.310 & 0.920 & 1.380 \\
\hline 0.716 & 0.711 & -0.210 & 0.150 & 0.650 & 1.070 & 2.100 \\
\hline 0.733 & 9.600 & -13.154 & -5.488 & -2.310 & 8.805 & 20.663 \\
\hline 25.239 & 17.510 & -8.815 & 10.855 & 25.073 & 35.573 & 59.520 \\
\hline 35.478 & 39.699 & 4.639 & 8.955 & 30.753 & 39.275 & 170.379 \\
\hline
\end{tabular}


$1 c$

Group Healing Variable

RP1 6 buccal volume

RP2 6 buccal volume

$\mathrm{SH} \quad 6$ buccal volume

RP1 6 buccal volume

RP2 6 buccal volume

$\mathrm{SH} \quad 6$ buccal volume

$\begin{array}{lll}\text { RP1 } & 6 & \text { ridge width } \\ \text { RP2 } & 6 & \begin{array}{l}\text { ridge width } \\ \text { ridge width } \\ \text { SH }\end{array} \\ & 6 & \\ \text { RP1 } & 6 & \text { ridge width } \\ \text { RP2 } & 6 & \text { ridge width } \\ \text { SH } & 6 & \text { ridge width }\end{array}$

$\begin{array}{ll}\text { RP1 } & 14 \\ \text { RP2 } & 14 \\ \text { SH } & 14\end{array}$

buccal volume

buccal volume

buccal volume

$\begin{array}{lllllll}\text { Mean } & \text { Std } & \text { Min } & \text { Q1 } & \text { Median } & \text { Q3 } & \text { Max } \\ -1.828 & 0.950 & -2.710 & -2.540 & -2.280 & -0.920 & -0.690 \\ -1.773 & 0.722 & -2.600 & -2.590 & -1.740 & -1.390 & -0.510 \\ -1.924 & 0.544 & -2.550 & -2.420 & -2.130 & -1.490 & -1.040 \\ & & & & & & \\ -0.110 & 0.341 & -0.440 & -0.430 & -0.050 & -0.010 & 0.380 \\ -0.749 & 0.402 & -1.240 & -0.960 & -0.850 & -0.600 & 0.040 \\ -1.437 & 0.657 & -2.490 & -1.840 & -1.550 & -0.720 & -0.650\end{array}$

$\begin{array}{rrrrrrr}-36.057 & 18.365 & -72.382 & -43.135 & -32.543 & -20.685 & -17.874 \\ -33.157 & 9.666 & -46.584 & -44.360 & -29.094 & -24.965 & -22.716 \\ -26.166 & 11.725 & -48.615 & -27.556 & -22.637 & -19.970 & -15.580 \\ & & & & & & \\ -21.401 & 21.841 & -69.509 & -21.610 & -13.860 & -10.370 & -4.955 \\ -28.813 & 8.242 & -43.359 & -32.628 & -26.266 & -24.028 & -17.673 \\ -29.580 & 16.234 & -55.017 & -37.861 & -30.047 & -12.686 & -11.823\end{array}$

$\begin{array}{lllllll}-2.324 & 0.800 & -3.570 & -3.290 & -1.900 & -1.690 & -1.670 \\ -1.613 & 0.880 & -3.080 & -1.770 & -1.635 & -1.170 & -0.390 \\ -1.653 & 0.961 & -3.110 & -2.370 & -1.525 & -0.880 & -0.510\end{array}$

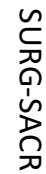

RP1 14 buccal volume

$-0.390$

$1.183-2.040-1.240$

0.240

0.500

0.590

RP2 14 buccal volume

$-1.220$

0.344

$-1.530$

$-1.460$

$-1.305$

$-0.980$

$-0.740$

$\mathrm{SH} \quad 14$

buccal volume

$-0.572$

$0.500-1.320$

$-0.780$

$-0.470$

$-0.250$

$-0.040$

$\begin{array}{rrrrrrr}-31.195 & 29.417 & -71.159 & -52.220 & -32.555 & -18.820 & 22.984 \\ -22.232 & 14.786 & -42.871 & -28.612 & -24.829 & -12.454 & 4.304 \\ -24.653 & 18.683 & -51.440 & -43.394 & -17.884 & -9.918 & -3.394\end{array}$

RP1 14 ridge width

$-5.901 \quad 25.811$

$-44.730 \quad-15.994$

$-5.451$

1.264

34.956

RP2 14 ridge width

$-22.407$

15.958

$-45.480 \quad-29.630$

$-22.102$

$-17.869$

7.251

SH 14 ridge width $\begin{array}{llll}-47.248 & -42.498 & -23.363 & -14.790\end{array}$ 